\title{
Assessment of the impact of the duration of construction on the effectiveness of the investment project
}

\author{
Elena Mikhaylova ${ }^{1 *}$ \\ ${ }^{1}$ Moscow State University of Civil Engineering, 129337, 26, Yaroslavskoe shosse, Moscow, Russia
}

\begin{abstract}
The article discusses the relevance and necessity of assessing the impact of the duration of construction on the economic efficiency of investments. Using a mathematical expression, the profit received by the investor during the life cycle of the direct investment process is described. The peculiarity of investment projects involving the creation of capital investment (real estate), is the period of time during which profit is impossible. This period of time is equal to the duration of construction, including installation of technological equipment and commissioning. An analytical description of the degree of influence of the duration of construction on the indicators of economic efficiency of the investment project (profitability and profitability of property) is proposed. On the basis of the learned expressions, a numerical experiment was performed and graphs were constructed. The results of the research prove the possibility of analytical description of the degree of influence of the duration of construction on the quantitative indicators describing the investment project (profitability (Bank interest), profitability of the created property). It seems that the described approach allows to carry out forecasts which reliability surpasses the results obtained, for example, by means of expert estimations. The proposed mathematical apparatus is much simpler than the methods of probability theory and fuzzy set theory.
\end{abstract}

\section{Introduction}

In this paper, investment projects involving the creation of capital construction projects are considered. Regulatory sources refer to such projects as "direct investments" or "capital investments". As a result of the implementation of such projects, real estate objects of industrial or non-industrial purpose are created, which are also called finished construction products. The investor financing the creation of construction products is interested in the fact that the money spent is returned in the amount exceeding the initial costs.

The quantitative measurement of the effectiveness of an investment project is the difference between the financial resources received after the implementation of the project and the initial costs attributed to the initial costs. The result of the calculation shows the

\footnotetext{
"Corresponding author: tranz-volga@,yandex.ru
} 
increment of investment capital per unit of cash. Capital gains are generated as a result of the sale of an object of capital investment, such as residential buildings, or when a profit is made as a result of the commercial exploitation of an object of real estate, such as industrial buildings or rent received for the transfer of finished construction products.

The duration of the investment project is usually represented in the form of a life cycle. The life cycle is considered as a set of stages (or phases). Each researcher in his own way represents the number and content of the life cycle. To assess the impact of the duration of construction on the effectiveness of investment projects, it is advisable to present the life cycle in the form of two terms. The first term is the time required to create a finished construction product. The second is the time during which the investor plans to return the invested financial resources and make a profit (income from investments). From the above reasoning, it is logical to assume that reducing the duration of construction increases the time during which real estate objects make a profit. Therefore, the increase in the length of time during which the objects of capital investments make a profit will inevitably lead to an increase in cash flow, and consequently to an increase in the profitability of the initial investment.

The above description of the characteristics of the implementation of investment projects providing creation of objects of capital investments should be attributed to actual problems arising in the implementation of projects to create production facilities (real estate for production purposes) and residential (real estate non-industrial) and civil buildings. The necessity and relevance of assessing the impact of construction duration on the economic efficiency of investments is emphasized in the published results of domestic [1,2] and foreign $[3,4]$ researchers.

The main purpose of investing is to obtain the expected benefit or net profit. The effectiveness of capital investments is often assessed by comparing different options for the ratio of net profit and reduced costs.

It is necessary to pay attention that in the present work the concept of Bank interest and efficiency of investments are considered as identical concepts. In this case, there is no difference between own or attracted investments, since in one and in the other case, the receipt of profit (income) for each unit of invested funds is presented as a necessary condition. There is a link between bank interest and high economic potential of construction [5].

Domestic and foreign practice of assessing the impact of the duration of construction on the economic efficiency of direct investment (capital investment) uses well-known principles and methods, the most common of them include:

1. expert evaluation $[6,7]$;

2. methods of probability theory (PERT and Monte Carlo) [4];

3. fuzzy set methods[3];

4. improvement of the widespread methods for the assessment of the World Bank and UNIDO, based on the study of cash flows [8,9].

It should be noted that the methodology for assessing the economic efficiency of investment projects of the World Bank and UNIDO does not reflect the specifics of the construction industry, does not take into account the uncertainties and variability of indicators included in the financial model. It focuses on consolidated cash flow forecasting. Questions of specificity of investment and construction projects are poorly worked out, volatility of the real estate market is not investigated.

Among the less common approaches to assessing the impact of the duration of construction on the value of the economic efficiency of the investment project are: 
1. calculation of the payback index, the value of which is directly proportional to the square root of the product of GRP and population and inversely proportional to the cost of construction [10];

2. "when assessing the economic efficiency of investment projects, the rate of absolute growth of productive capital; instead of the internal rate of return of the investment to calculate the ratio of their effectiveness, and the payback period (the time of doubling of productive capital) as the inverse set-term economic efficiency» [11];

3. integrating the escalation based on the method of adjustment items [12];

4. calculation of the entropy of the process of creating construction products [13].

These approaches can be used to assess the economic efficiency of the investment project, depending on the duration of construction. The General disadvantage of the above research results is the absence of a direct mathematical relationship between the duration of construction and the return on direct investment. This paper presents an approach that addresses this common shortcoming.

Objective: on the basis of logical reasoning to establish an algebraic relationship between the value of the economic efficiency of direct investment (return on investment) and the duration of construction.

To achieve the goal the following tasks were solved:

1. on the basis of logical reasoning, an algebraic record describing economic indicators throughout the life cycle of the process of direct investment (capital investment);

2. by means of the simplest algebraic transformations the mathematical expression describing dependence of economic efficiency of direct investments on duration of construction is deduced;

3. for the mathematical dependence of the value of the economic efficiency of direct investment on the duration of construction, a numerical experiment was performed and a graphic image was obtained.

\section{Materials and Methods}

At the initial stage of the formation of the investment plan, it is necessary to determine the volume of investment financing, the approximate value of the expected profit, the likely construction time and the forecast estimate of the duration of operation of the object. The calculation of these indicators is the basis of investment design and is further used for the preparation of a business plan. Obtaining preliminary values of these indicators can be carried out in various ways. The methods of logic, elementary algebra and analytical geometry were applied in this work.

The basis of the research methodology is the following sequence of formalized reasoning:

1. The investor expects to profit from the spent financial resources in the amount of:

$$
D=I+I i_{t} t
$$

where $\mathrm{D}$ is the amount of money expected by the investor as a result of the placement of financial resources (financing of the investment project), expressed in monetary units;

- I-initial investment amount expressed in monetary units;

- $i_{\mathrm{t}}$-the expected return on investment (or Bank interest rate), expressed as a percentage per unit time $t$;

- $t$ - the number of units of time during which the full implementation of the investment project is expected (that is, until the investor receives the amount of the placed capital and profit). 
2. The borrower (the initiator of the project) must ensure the cash flow to the investor in the amount of at least "D" during the implementation of the project. The source for the formation of such an amount is profit. The rules for calculating income tax provide for the return of borrowed funds from net income, and the costs associated with the payment of interest are attributed to direct costs. In this regard, the initiator of the project needs to ensure that the amount of profit for the time " $t$ ", which will be equal to (or will exceed) the obligations to the investor (in the amount of "D", calculated by formula 1).The above reasoning is described by a mathematical expression:

$$
d_{t} t \geq \frac{I}{\left(1-\tau_{d}\right)}+I i_{t} t
$$

where $d_{t}$ is the profit received by the initiator of the project per unit of time " $\mathrm{t}$ ", expressed in monetary units;

- I-initial investment amount expressed in monetary units;

- $i_{t}$-the expected return on investment (or Bank interest rate), expressed as a percentage per unit time $\mathrm{t}$;

$-t$ - the number of units of time during which the full implementation of the investment project is expected (that is, until the investor receives the amount of the placed capital and profit);

- $\tau_{d}$ - income tax rate set for the national economy, expressed as a percentage.

3 . The features of investment projects involving the creation of capital investment (real estate), should include a period of time during which profit is impossible. This is due to the fact that the investment project is not brought to a state in which it can be sold or begin to create a profit (produce products).In order to take into account this feature of investment projects in the construction sector, it is necessary to adjust formula 2 in terms of the period of time during which profits can be obtained. Such an adjustment implies a reduction in the period of time during which it is possible to make a profit on the value of the duration of construction (creation of production facilities, that is, construction, including installation and commissioning of technological equipment). Changes of formula 2 have the form:

$$
d_{t}\left(t-t_{B}\right) \geq \frac{I}{\left(1-\tau_{d}\right)}+I i_{t} t
$$

where $t_{B}$ is the duration of construction of the capital construction facility, including installation of equipment and commissioning, in units of time;

- $\tau_{d^{-}}$income tax rate applicable in the national economy, expressed as a percentage.

The studies were performed using mathematical expression 3. From it, it is not difficult to establish an algebraic relationship between the return on investment (it) and the duration of construction $\left(\mathrm{t}_{\mathrm{B}}\right)$.

\section{Results}

If in formula 3 both parts of the equation are divided by "I", the income tax rate is assumed to be equal to $\tau_{d}=20 \%$, the duration of the investment period is set to $t=100$ (units of time), and the duration of construction is represented as a ratio $\frac{t_{B}}{t}=x$ ( $x$ will show what part of the duration of the investment project takes construction), then after the simplest algebraic transformations: 


$$
p(1-x)-0,0125>i_{t}
$$

where $p=\frac{d_{t}}{I}$ is the profitability of the property, measured in relative units;

- $x$-the share occupied by the duration of construction in the total duration of the investment project;

- $i_{t}$-return on investment (Bank interest rate).

The results of the numerical experiment performed according to formula 4 are given in table. 1 .

Table 1. Change in the return on investment depending on the change in the duration of construction.

\begin{tabular}{|c|c|c|c|c|}
\hline \multirow{2}{*}{ № } & The relative change & \multicolumn{3}{|c|}{ Value of return on investment, $\mathbf{i}_{\mathbf{t}}$} \\
\cline { 3 - 5 } & \multirow{2}{*}{$\begin{array}{c}\text { in duration of the } \\
\text { construction, } \mathbf{x}\end{array}$} & $\mathbf{p = 0 , 0 2}$ & $\mathbf{p}=\mathbf{0 , 0 2 5}$ & $\mathbf{p}=\mathbf{0 , 0 3}$ \\
\cline { 3 - 5 } & $\mathbf{2}$ & $\mathbf{i}_{\mathbf{t}}$ & $\mathbf{i}_{\mathbf{t}}$ & $\mathbf{i}_{\mathbf{t}}$ \\
\hline $\mathbf{1}$ & $\mathbf{3}$ & $\mathbf{4}$ & $\mathbf{5}$ \\
\hline 1 & 0,05 & 0,0065 & 0,0113 & 0,0160 \\
\hline 2 & 0,10 & 0,0055 & 0,0100 & 0,0145 \\
\hline 3 & 0,15 & 0,0045 & 0,0088 & 0,0130 \\
\hline 4 & 0,20 & 0,0035 & 0,0075 & 0,0115 \\
\hline 5 & 0,25 & 0,0025 & 0,0063 & 0,0100 \\
\hline 6 & 0,30 & 0,0015 & 0,0050 & 0,0085 \\
\hline 7 & 0,35 & 0,0005 & 0,0038 & 0,0070 \\
\hline 8 & 0,40 & $-0,0005$ & 0,0025 & 0,0055 \\
\hline 9 & 0,45 & $-0,0015$ & 0,0013 & 0,0040 \\
\hline 10 & 0,50 & $-0,0025$ & 0,0000 & 0,0025 \\
\hline
\end{tabular}

The linear nature of the dependence of investment returns on the duration of construction (formula 4) should be considered taking into account the value of the profitability of the property (columns 3-5, table. 1). The most obvious influence of the property profitability indicator on the return on investment is presented in Fig. 1.

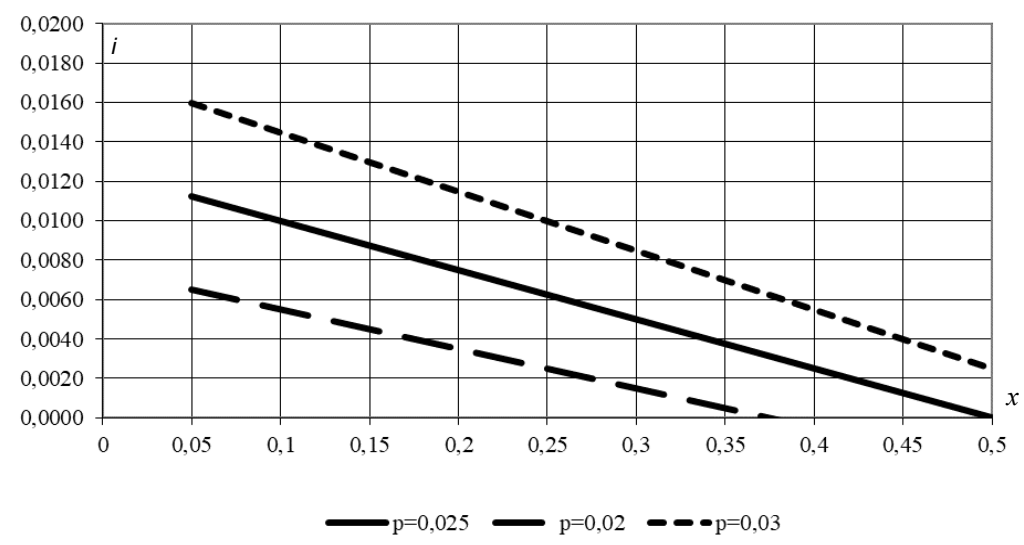

Figure 1. Dependence of investment profitability on the duration of construction in the investment project. 
Figure 1 shows that with an increase in the share of construction time in the total period of implementation of the investment project, the return on investment decreases.

The main feature of the schedule for the proposed construction object is the fact that it is calculated in the absence of project documentation. Therefore, when carrying out calculations, enlarged norms of the duration of the main types of work, estimated calculations and projects of work on analogical objects of construction, standard technological maps and other information materials are used. In this regard, the graph can be used only when making approximate calculations and making initial decisions. In the future, during the development of the project and its implementation, the schedule is refined on the basis of the organizational and technological decisions on the construction of the building for the interval of values of the duration of construction adopted by the investor at the initial stage of formation of the investment idea.

The presented solution of the problem can be conditionally called a "direct problem". As inverse problems, the greatest practical interest, from the point of view of the author, is to find the value of the profitability of property ( $p)$, which is able to achieve a given level of profitability (set Bank interest).

The results of solving this problem are given in table. 2 .

Table 2.Change of profitability of property depending on change of duration of construction

\begin{tabular}{|c|c|c|c|c|}
\hline \multirow{2}{*}{ № } & The relative change & \multicolumn{3}{|c|}{ The value of property profitability for an investment project, $\boldsymbol{p}$} \\
\cline { 3 - 5 } & in the duration of the & $\boldsymbol{i}_{t}=\mathbf{0 , 0 0 5}$ & $\boldsymbol{i}_{\boldsymbol{t}}=\mathbf{0 , 0 1}$ & $\boldsymbol{i}_{\boldsymbol{t}}=\mathbf{0 , 0 1 5}$ \\
\cline { 3 - 5 } & construction, $\boldsymbol{x}$ & $\boldsymbol{p}$ & $\boldsymbol{p}$ & $\boldsymbol{p}$ \\
\hline $\boldsymbol{I}$ & $\mathbf{2}$ & $\mathbf{3}$ & $\mathbf{4}$ & $\mathbf{5}$ \\
\hline 1 & 0,05 & 0,0184 & 0,0237 & 0,0289 \\
\hline 2 & 0,10 & 0,0194 & 0,0250 & 0,0306 \\
\hline 3 & 0,15 & 0,0206 & 0,0265 & 0,0324 \\
\hline 4 & 0,20 & 0,0219 & 0,0281 & 0,0344 \\
\hline 5 & 0,25 & 0,0233 & 0,0300 & 0,0367 \\
\hline 6 & 0,30 & 0,0250 & 0,0321 & 0,0393 \\
\hline 7 & 0,35 & 0,0269 & 0,0346 & 0,0423 \\
\hline 8 & 0,40 & 0,0292 & 0,0375 & 0,0458 \\
\hline 9 & 0,45 & 0,0318 & 0,0409 & 0,0500 \\
\hline 10 & 0,50 & 0,0350 & 0,0450 & 0,0550 \\
\hline
\end{tabular}

The nature of the dependence of the profitability of the property on the duration of construction (formula 4) is nonlinear. The results presented in table. 2 (columns 3-5) are calculated taking into account the change in the specified level of return (Bank interest). The impact of the yield indicator is most clearly shown in Fig. 2.

On the basis of the graphs presented in figures 1 and 2, the investor can previously accept for further development a rather narrow range of values of the duration of construction. he implementation of the following stages of construction, organizational and technological design, etc. will be carried out taking into account the feasibility studies of the effectiveness of decisions taken by the investor.

Consider the dependence of the return on investment profitability of the property at three fixed values of the duration of construction, the results are presented in table 3 . 


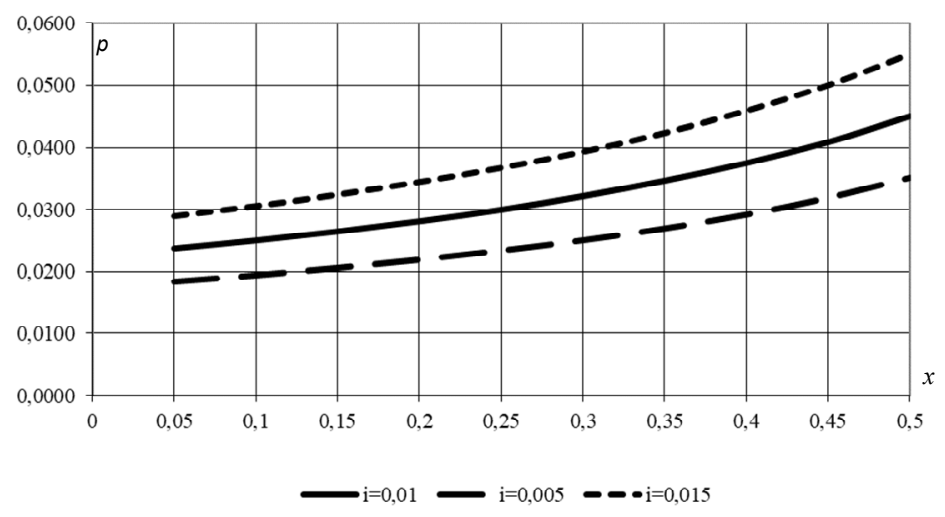

Figure 2. Dependence of profitability of property on duration of construction in the investment project

Table 3. Changes in the return on investment depending on the profitability of the property

\begin{tabular}{|c|c|c|c|c|}
\hline \multirow{2}{*}{ № } & \multirow{2}{*}{$\begin{array}{c}\text { Return on } \\
\text { investment project } \\
\text { property, }\end{array}$} & \multicolumn{3}{|c|}{ Value of return on investment, $\mathbf{i}_{\mathbf{t}}$} \\
\cline { 3 - 5 } & $\mathbf{2}$ & $\mathbf{x}=\mathbf{0 , 1}$ & $\mathbf{x}=\mathbf{0 , 2}$ & $\mathbf{x = 0 , 3}$ \\
\hline $\mathbf{1}$ & $\mathbf{i}_{\mathbf{t}}$ & $\mathbf{\mathbf { i } _ { \mathbf { t } }}$ & $\mathbf{i}_{\mathbf{t}}$ \\
\hline 1 & 0,025 & $\mathbf{3}$ & $\mathbf{4}$ & $\mathbf{5}$ \\
\hline 2 & 0,035 & 0,01 & 0,0075 & 0,005 \\
\hline 3 & 0,045 & 0,019 & 0,0155 & 0,012 \\
\hline 4 & 0,055 & 0,028 & 0,0235 & 0,019 \\
\hline 5 & 0,065 & 0,037 & 0,0315 & 0,026 \\
\hline 6 & 0,075 & 0,046 & 0,0395 & 0,033 \\
\hline 7 & 0,085 & 0,055 & 0,0475 & 0,04 \\
\hline 8 & 0,095 & 0,064 & 0,0555 & 0,047 \\
\hline 9 & 0,105 & 0,073 & 0,0635 & 0,054 \\
\hline 10 & 0,115 & 0,082 & 0,0715 & 0,061 \\
\hline
\end{tabular}

The dependence of investment profitability on the profitability of property in the investment project is linear, which is clearly shown in figure 3 .

In real practice, there is often a situation when there is a need to compare the organizational and technological models of projects (or one project) with different construction duration (regulatory, settlement, contractual). In this case, the total shortest life cycle of the project (including the creation of finished products), which includes the investment, design, construction and production stages, is found. Next is the share of normative, estimated or contractual duration of construction in the total life cycle of the project, determined by the return on investment and profitability of the property.

Figure 3 shows a graph of the dependence of the return on investment profitability of the property at different durations of construction. On the basis of this schedule it is possible to make decisions on expediency of a choice of the project or organizational and technological model of realization of object of construction. 


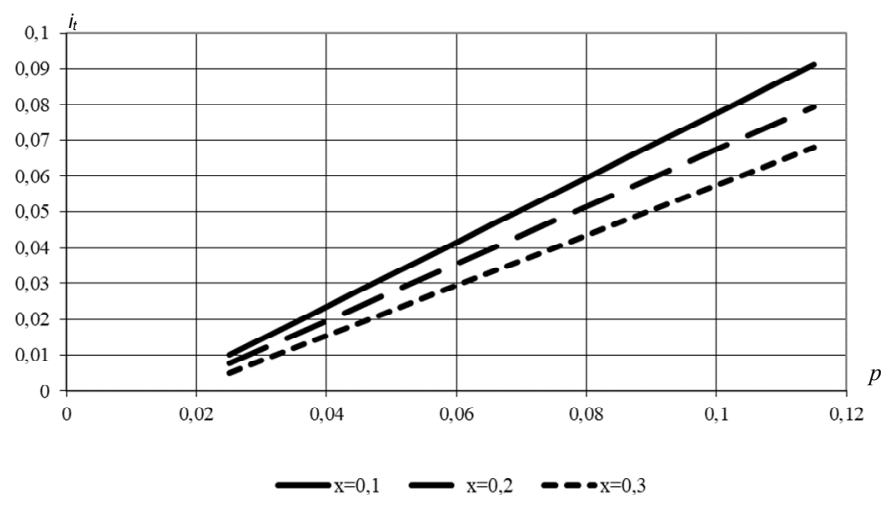

Figure3. The dependence of the return on investment from a profitability of the assets in an investment project

The results of the research prove the possibility of analytical description of the degree of influence of the duration of construction on the quantitative indicators describing the investment project (profitability (Bank interest), profitability of the created property).

\section{Discussion}

The calculations showed that the shorter the duration of the construction of the object, the higher the return on investment with the same profitability of the property.

Reducing the construction time can be achieved by using the following factors:

1. organizational-establishment of two-shift and three-shift modes of operation, organization of flow-combined fronts of works, etc.;

2. use of means of mechanization-high-performance construction machines and mechanisms;

3. design manufacturability of solutions (for example, the use of complete-block construction methods).

However, for any object of construction there is a minimum period of its construction, which is almost impossible to reduce. At the same time, when approaching the minimum duration of construction, the estimated cost of the object, and therefore the required investments, significantly increases. It is possible to determine the rationally justified duration of construction at which the ratio of profit and cost will be the most cost-effective using the Black-Scholes model [14].

It seems that the described approach allows you to make predictions the reliability of which exceeds the results obtained, for example, with the help of expert assessments[6,7]. The proposed mathematical apparatus is much simpler than the methods of probability theory $[4,15]$ and fuzzy set theory [3].

It should be noted that the proposed analytical description of the degree of influence of the duration of construction on the indicators of economic efficiency of the investment project (profitability and profitability of property), significantly expands the possibilities of practical application of the Black - Scholes model and contributes to a significant increase in the reliability of the results. 


\section{Conclusion}

1. The obtained dependences establish the quantitative value of the degree of influence of the duration of construction on the indicators of economic efficiency of the project of capital investments (profitability and profitability of the created property).

2. The practical application of analytical dependencies in economic calculations significantly increases the reliability of the calculated values. This allows the investor to justify the effectiveness of investments in the construction of the object on the basis of information received in the required volume.

3. The proposed approach to assessing the impact of duration on the efficiency of direct investment significantly expands the possibilities of using well-known and proven methods, for example, the PERT system, the Black - Scholes model and others.

\section{Reference}

1. A.A. Volkov, Z. R. Tuskaeva, Vestnik MGSU, 12, 9(108), 990-998. doi: 10.22227/1997-0935.2017.9.990-998

2. V.N. Kabanov, Mag. Civ. Eng. No. 1, 59-67 (2018) doi: 10.18720/MCE.77.6.

3. S. M. A. Tabei, M. Bagherpour, A. Mahmoudi, Peri. Polyt. Ci. Eng., .№ 63 (2), 647659. (2019) doi.org/10.3311/PPci.13402

4. Jin, Z. Kim, J. Hyun, C.-T.; Han, Susta., № 11 (2019) doi.org/10.3390/su11143828 S.

5. A.A. Lapidus, I.L. Abramov, WMCAUS, 603 (2019) doi:10.1088/1757899X/603/5/052079

6. L. M. Amusan. A. Afolabi, R. Ojelabi, I. Omuh, H. I. Okagbue, Dat. Brief., 17, 13201325 (2018) doi.org/10.1016/j.dib.2018.02.035.

7. N. Chileshe, R. Rameezdeen, M. R. Hosseini, I. Martek, Wa. Man., 79, 48-57 (2018) doi.org/10.1016/j.wasman.2018.07.013

8. M. Tavakolan, S. Nikoukar, Int. J. Const. Man. DOI:10.1080/15623599.2019.1619439

9. D. F. Goncharenko, I. A. Minaloc, Aca. Ci. Eng. Archa., № 1, 94 - 101 (2019) doi: 10.30838/J.BPSACEA.2312.260319.94.411

10. P.P. Oleinik, T.K. Kuzmina., V. Zenov, Matec Web Conf., 86, 5019 (2016)

11. R. Minunno, T. O’Grady, G.M. Morrison, R.L. Gruner, M. Colling, J. Build., 8 (9) (2018) URL: doi.org/10.3390/buildings8090125

12. S. Ju-yong, Lee K. Dong-jin, Kor. J. Constr. Engi. Manag., 20(3), 3-11 (2019) doi.org/10.6106/KJCEM.2019.20.3.003

13. P. Saieg, E. D. Sotelino, D. Nascimento, R. Caiado, J. Clean. Prod., 174, 788-806, (2018) Doi.org/10.1016/j.jclepro.2017.11.030

14. E. Mikhaylova, MATEC Web Confe,, 265 doi.org/10.1051/matecconf/201926507006

15. Yu. B. Kalugin, Maga. Civ. Eng., 7, 70-80 (2016) Doi: 10.5862/MCE.67.7 